\title{
New potentially antihypertensive peptides liberated in milk during fermentation with selected lactic acid bacteria and kombucha cultures
}

\author{
Ebrahim Elkhtab, ${ }^{*} \dagger$ Mohamed El-Alfy, $\dagger$ Mohamed Shenana, $\dagger$ Abdelaty Mohamed, $\dagger$ and Ahmed E. Yousef ${ }^{* 1}$ \\ *Department of Food Science and Technology, The Ohio State University, Columbus 43210 \\ †Department of Dairy Science, Faculty of Agriculture, Benha University, Moshtohor, Qalyubia 13736, Egypt
}

\begin{abstract}
Compounds with the ability to inhibit angiotensinconverting enzyme (ACE) are used medically to treat human hypertension. The presence of such compounds naturally in food is potentially useful for treating the disease state. The goal of this study was to screen lactic acid bacteria, including species commonly used as dairy starter cultures, for the ability to produce new potent ACE-inhibiting peptides during milk fermentation. Strains of Lactobacillus acidophilus, Lactobacillus casei, Lactobacillus delbrueckii ssp. bulgaricus, Lactobacillus helveticus, Lactobacillus paracasei, Lactococcus lactis, Leuconostoc mesenteroides, and Pediococcus acidilactici were tested in this study. Additionally, a symbiotic consortium of yeast and bacteria, used commercially to produce kombucha tea, was tested. Commercially sterile milk was inoculated with lactic acid bacteria strains and kombucha culture and incubated at $37^{\circ} \mathrm{C}$ for up to $72 \mathrm{~h}$, and the liberation of ACE-inhibiting compounds during fermentation was monitored. Fermented milk was centrifuged and the supernatant (crude extract) was subjected to ultrafiltration using 3- and $10-\mathrm{kDa}$ cut-off filters. Crude and ultrafiltered extracts were tested for ACE-inhibitory activity. The 10-kDa filtrate resulting from L. casei ATCC 7469 and kombucha culture fermentations $(72 \mathrm{~h})$ showed the highest ACE-inhibitory activity. Two-step purification of these filtrates was done using HPLC equipped with a reverse-phase column. Analysis of HPLC-purified fractions by liquid chromatography-mass spectrometry/ mass spectrometry identified several new peptides with potent ACE-inhibitory activities. Some of these peptides were synthesized, and their ACE-inhibitory activities were confirmed. Use of organisms producing these unique peptides in food fermentations could contribute positively to human health.
\end{abstract}

Received May 11, 2017.

Accepted August 15, 2017.

${ }^{1}$ Corresponding author: yousef.1@osu.edu
Key words: lactic acid bacteria, kombucha, angiotensin converting enzyme, bioactive peptide, liquid chromatography

\section{INTRODUCTION}

The nutritional value of milk has been well documented, and newer discoveries revealed bioactive milk components with the potential to improve human health. Newly identified bioactivities include modulation of gastrointestinal functions, immunoregulation, disease defense, and enhancement of intestinal probiotic microbiota (Schanbacher et al., 1998; Bauman et al., 2006). Milk contains ingredients that serve as precursors of peptides with important biological and physiological characteristics. Bioactive peptides are defined as specific protein fragments that have a positive effect on body functions or conditions and may ultimately influence health (Kitts and Weiler, 2003). Many bioactive peptides are potentially suitable for formulation of functional foods, nutraceuticals, and natural drugs (Haque et al., 2009).

According to World Health Organization estimates, high blood pressure (hypertension) affects 1 billion people in the world, leading to heart attacks and strokes. Furthermore, it is estimated that hypertension kills 9 million people annually (World Health Organization, 2013). The body's renin-angiotensin-aldosterone system is considered to be responsible for the regulation of blood pressure. The lungs' angiotensin-converting enzymes (ACE) catalyze the conversion of angiotensin I to angiotensin II, which is considered the main participant in increasing blood pressure (Sancho et al., 1976; Niarchos et al., 1979). Inhibition of ACE minimizes the formation of angiotensin II, thus alleviating blood pressure increase by the renin-angiotensin-aldosterone system (Niarchos et al., 1979). Hypertension is treated with synthetic drugs such as captopril and enalapril, but many undesirable side effects have been reported (Atkinson and Robertson, 1979). Considering the increased incidence of high blood pressure in most parts of the world (López-Fandiño et al., 2006), it would be 
greatly beneficial if ACE-inhibiting peptides could be produced naturally in food, particularly during milk fermentation.

Bioactive peptides with ACE-inhibitory activity, developed during milk fermentation, are the focus of this study. The ACE-inhibitory peptides, liberated from milk proteins, showed antihypertensive activity when they were orally administered to spontaneously hypertensive rats (Chen et al., 2007; Quirós et al., 2007). The fermented milk products containing Ile-Pro-Pro and Val-Pro-Pro decreased blood pressure and enhanced the impaired endothelium-dependent relaxation function of mesenteric arteries in salt-loaded Goto-Kakizaki rats (Jäkälä et al., 2009). Although researchers recently have identified many bioactive food components, there is a need to discover new promising ACE-inhibitory peptides. It is of value to identify conditions that favor the generation of these peptides in currently produced dairy products and in new products designed to be rich in ACE inhibitors. Hence, this study aimed to determine the ability of selected lactic acid bacteria (LAB) and other beneficial microorganisms to produce ACEinhibitory peptides during milk fermentation.

\section{MATERIALS AND METHODS}

\section{Ingredients and Cultures}

Ultra-high temperature-treated milk (Horizon Organic, Broomfield, CO) was purchased from a local market. Different strains of LAB were obtained from the culture collection of the food microbiology laboratory of the Ohio State University, Columbus, and tested in this study. These strains were Lactobacillus acidophilus, Lactobacillus casei ATCC 7469, Lactobacillus delbrueckii ssp. bulgaricus, Lactobacillus helveticus, Lactobacillus paracasei 6A, Lactococcus lactis ATCC 11454, Leuconostoc mesenteroides ATCC 14935, and Pediococcus acidilactici PO2. All bacterial strains were transferred from frozen stock into De Man, Rogosa and Sharpe (MRS) broth and incubated at $37^{\circ} \mathrm{C}$ for $24 \mathrm{~h}$ before use in milk fermentation. Kombucha tea culture was purchased from Kombucha Brooklyn (Brooklyn, NY), and organic green tea (Uncle Lee's Tea, South El Monte, CA) was purchased from a local market.

\section{Preparation of ACE from Rabbit Lung}

The ACE was prepared experimentally as described by Cushman and Cheung (1971) with modifications. Lung tissue $(20 \mathrm{~g})$ from 2 freshly slaughtered rabbits was obtained from local farms (Columbus, $\mathrm{OH}$ ). Lung tissue was cut into pieces and washed with precooled potassium phosphate buffer $(0.1 \mathrm{M}$, containing $0.3 \mathrm{M}$ $\mathrm{NaCl} ; \mathrm{pH}$ 8.3) to get rid of blood. The washed rabbit lung pieces were homogenized by blending for $3 \mathrm{~min}$ in the same buffer at a ratio of 1:10 (wt/vol). The homogenized lung tissues were centrifuged at $10,000 \times g$ and $4^{\circ} \mathrm{C}$ for $40 \mathrm{~min}$. The tissue supernatant was dialyzed at $4^{\circ} \mathrm{C}$ for $24 \mathrm{~h}$ using dialysis tubing with 12 - to $14-\mathrm{kDa}$ cut-off (Spectrum Medical Industries Inc., Houston, TX) against 20 volumes of the phosphate buffer. The buffer was exchanged 4 times. The dialyzed extract was used as the source of the ACE.

\section{Determination of the Activity of ACE from Rabbit Lung}

Activity of ACE in the rabbit lung extract was determined as described by Cushman and Cheung (1971) as follows. Solution of hippuryl-L-histydyl-L-leucine (HHL; MP Biomedicals, Solon, OH) was prepared at the concentration of $5 \mathrm{~m} M$ (in $0.1 M$ potassium phosphate buffer containing $0.3 \mathrm{M} \mathrm{NaCl}$; final $\mathrm{pH}=8.3$ ) was used as an ACE substrate. To assay for enzyme activity, a portion $(250 \mu \mathrm{L})$ of the HHL solution was mixed with $70 \mu \mathrm{L}$ of ACE preparation and the mixture was incubated at $37^{\circ} \mathrm{C}$ for $30 \mathrm{~min}$. The reaction was terminated by the addition of $250 \mu \mathrm{L}$ of $1 \mathrm{M} \mathrm{HCl}$. The hippuric acid, liberated in the reaction mixture, was extracted using ethyl acetate with agitation for $20 \mathrm{~s}$ and centrifugation at $3,000 \times g$ for $20 \mathrm{~min}$ at $4^{\circ} \mathrm{C}$. The top layer was collected and the solvent was removed by evaporation in a water bath at $100^{\circ} \mathrm{C}$ for $1 \mathrm{~h}$ within a chemical hood. The remaining residue was dissolved in $1 \mathrm{~mL}$ of HPLC-grade water, and absorbance (A) was measured at $228 \mathrm{~nm}$ in a spectrophotometer. The blank solution was prepared following the same method, but $\mathrm{HCl}$ was mixed immediately before the $\mathrm{ACE}$ was added. One unit of ACE activity was defined as the amount required to catalyze the formation of 1 $\mu$ mol of hippuric acid from HHL solution (prepared as described previously) in $1 \mathrm{~min}$ at $37^{\circ} \mathrm{C}$ under standard assay conditions. The ACE activity was calculated as follows: ACE activity $=\left[\mathrm{A}_{228} \mathrm{~nm}\right.$ (reaction mixture) $\mathrm{A}_{228} \mathrm{~nm}$ (blank) $] \times 5.6 \times 10^{-3}$.

\section{Fermentation of Green Tea by Kombucha Culture}

Kombucha fermentation was done as described by Reiss (1994) with modifications. One liter of water was boiled for $10 \mathrm{~min}$ and then $100 \mathrm{~g}$ of sucrose and 7 bags $(\sim 10 \mathrm{~g}$ each $)$ of green tea were added with mild stirring. The mixture was held at room temperature for $30 \mathrm{~min}$, and then the tea bags were removed. The tea 
solution was transferred into a 2-L clean glass jar, held until its temperature decreased to ambient temperature $\left(24 \pm 3^{\circ} \mathrm{C}\right)$, and inoculated with $25 \mathrm{~g}$ of commercial kombucha inoculum. The jar was covered with clean cheesecloth, and the fermentation was carried out at 22 to $24^{\circ} \mathrm{C}$ for $2 \mathrm{wk}$. The resulting fermented tea was used as an inoculum for milk fermentation.

\section{Isolation and Identification of Kombucha Culture Microorganisms}

Microorganisms in kombucha culture used in this study were grown and isolated on the following selective and nonselective media: MRS broth and agar (Oxoid, Basingstoke, UK), plate count agar (Becton Dickinson, Franklin Lakes, NJ), tryptic soy broth (Becton Dickinson), tryptic soy agar (Fisher Scientific, Hampton, NH), and potato dextrose agar (Becton Dickinson) acidified by the addition of $1 \%$ of tartaric acid solution (10\%). Acetic acid bacteria were isolated and enumerated on a medium described by Yamada et al. (1999). The medium contained $2.0 \%$ glucose, $0.5 \%$ ethanol, $0.5 \%$ peptone, $0.8 \%$ yeast extract, $0.7 \%$ calcium carbonate, and $1.2 \%$ agar. For example, portions of kombucha culture were suspended in MRS broth and tryptic soy broth and incubated at $30^{\circ} \mathrm{C}$ for $24 \mathrm{~h}$. The incubated culture was streaked for isolation on MRS agar and tryptic soy agar. Pure and single colonies were isolated, suspended in MRS broth medium, and incubated at $30^{\circ} \mathrm{C}$ for $24 \mathrm{~h}$.

Strains were identified by sequencing the $16 \mathrm{~S}$ ribosomal DNA (rDNA) gene for bacterial isolates (Weisburg et al., 1991) and the 26S rDNA gene for yeast isolates (Kurtzman and Robnett, 1998). Genomic DNA of strains was purified using a DNA isolation kit (DNeasy Blood and Tissue kit; Qiagen, Valencia, CA). The $16 \mathrm{~S}$ rDNA and $26 \mathrm{~S}$ rDNA sequences were amplified by PCR using 2 sets of universal primers specific for the rDNA genes. The PCR amplification was performed using a Taq DNA polymerase kit (Qiagen) in a thermocycler under the following conditions: initial denaturation at $94^{\circ} \mathrm{C}$ for 3 min followed by 35 cycles of $1 \mathrm{~min}$ at $94^{\circ} \mathrm{C}, 1 \mathrm{~min}$ at $52^{\circ} \mathrm{C}$, and 2 min at $72^{\circ} \mathrm{C}$. A final extension was carried out at $72^{\circ} \mathrm{C}$ for $10 \mathrm{~min}$. The amplified PCR product was purified using a gel extraction kit (QIAquick; Qiagen). At the end of the $\mathrm{PCR}$ cycle, the PCR products were stored at $-20^{\circ} \mathrm{C}$ until sequenced.

The DNA was sequenced using a DNA analyzer (Applied Biosystems, Foster City, CA) at the Plant-Microbe Genomics Facility at The Ohio State University. Strain identification was done using the Ribosomal Database Project (http://rdp.cme.msu.edu/index.jsp) as recommended by Cole et al. (2014).

\section{Preparation of Bioactive Peptides During Milk Fermentation}

Fermentations were carried out as described by Hernández-Ledesma et al. (2004) with modifications. Portions $(400 \mu \mathrm{L})$ of LAB or kombucha cultures were transferred into $40-\mathrm{mL}$ aliquots of UHT milk in $50-\mathrm{mL}$ sterile tubes. Inoculated milk was incubated at $37^{\circ} \mathrm{C}$, and samples were collected at $0,24,48$, and $72 \mathrm{~h}$ and analyzed for changes in $\mathrm{pH}$, microbial population, and ACE-inhibitory activities. To monitor changes in starter culture population during the fermentation, samples were plated on MRS agar and incubated at $37^{\circ} \mathrm{C}$ for $48 \mathrm{~h}$. Assay for ACE-inhibitory activity was done after samples were heated in a water bath at $90^{\circ} \mathrm{C}$ for 10 min to stop fermentation; then, $\mathrm{pH}$ was adjusted to 3.8 with $50 \%$ lactic acid solution, and the mixture was centrifuged at $7,000 \times g$ for $10 \mathrm{~min}$. The heated culture supernatant was collected, and its $\mathrm{pH}$ was readjusted to 8.3 using $50 \% \mathrm{KOH}$ solution, centrifuged at the same conditions described previously, and filtered (Whatman 1 filter paper, St. Louis, MO) to remove any sedimented proteins. Portions of the clear supernatant (crude extract) were ultrafiltered to remove macromolecules and collect small to medium peptides, which are targeted as potential ACE inhibitors. Therefore, crude extracts were filtered through 3- or 10-kDa cutoff filters (Amicon Ultracel; Merck Millipore Ltd., Billerica, MA) following the manufacturer's instructions. The filtrates of crude extracts were stored at $-20^{\circ} \mathrm{C}$ until further examination. Three replicates of the experiment were performed.

\section{Determination of ACE-Inhibitory Activity in Products of Milk Fermentation}

The following fermentate preparations were tested for ACE inhibition: (1) unfiltered supernatant (crude extract), (2) 3-kDa filtrate, and (3) 10-kDa filtrate. For ACE inhibition, the method of Cushman and Cheung (1971) was followed with several modifications. A portion $(200 \mu \mathrm{L})$ of HHL solution was mixed with 75 $\mu \mathrm{L}$ of phosphate buffer ( $R$ reaction) or with $75 \mu \mathrm{L}$ of fermented milk fermentate or filtrate ( $I$ reaction) for 2 min at $37^{\circ} \mathrm{C}$. The reaction was started by adding $70 \mu \mathrm{L}$ of ACE solution (0.008 unit/mL), and the mixture was incubated at $37^{\circ} \mathrm{C}$ for $30 \mathrm{~min}$ in a water bath. The rest of the steps were repeated as described earlier for ACE activity determination.

The percentage ACE inhibition was calculated as follows:

$$
\begin{gathered}
\% \mathrm{ACE} \text { inhibition }=\{[(R-B r)-(I-B i)] / \\
(R-B r)\} \times 100
\end{gathered}
$$


where $R$ is the absorbance of the reaction mixture without inhibitor, $\mathrm{Br}$ is the absorbance of the blank of $R, I$ is the absorbance of the reaction in the presence of the inhibitory fermentate or filtrate, and $B i$ is the absorbance of the blank of $I$.

\section{Purification of the Most Active ACE-Inhibitory Peptides}

The $10-\mathrm{kDa}$ fermentation filtrates of $L$. casei ATCC 7469 , L. paracasei $6 \mathrm{~A}$, and kombucha cultures showed the highest ACE-inhibition activity; therefore, these filtrates were used to purify the inhibitors by HPLC (Hewlett Packard Agilent 1050; Agilent Technologies, Palo Alto, CA). The HPLC system was equipped with a C18 column $(250 \mathrm{~mm} \times 4.6 \mathrm{~mm} ; 5 \mu \mathrm{m}$ particle size; Thermo Scientific Inc., Waltham, MA). Solvent A was water-trifluoroacetic acid (1,000:1; vol/vol), and solvent $\mathrm{B}$ was acetonitrile-trifluoroacetic acid (1,000:1; vol/ vol). The fermentation filtrates were filtered through $0.45-\mu \mathrm{m}$ polyvinylidene fluoride membrane (Millex-HV; Merck Millipore Ltd.) before injection into the HPLC system. For each run, an aliquot $(100 \mu \mathrm{L})$ of the $10-\mathrm{kDa}$ filtrate was loaded and separated on the column by a linear gradient of zero to $100 \%$ solvent B over 30 min at a flow rate of $1 \mathrm{~mL} / \mathrm{min}$. Elution was monitored using a UV detector at a wavelength of $215 \mathrm{~nm}$. Fractions from each minute of retention time were collected automatically using a fraction collector (Waters Corp., Milford, MA). Fractions with the same retention time from multiple runs were pooled and dried in a chemical hood; the resulting residues were dissolved in HPLC-grade water, and $\mathrm{pH}$ was adjusted to 8.3. The ACE-inhibition activity of each pooled faction was determined as described before. Fractions active against ACE were stored at $-20^{\circ} \mathrm{C}$ until further analysis.

The HPLC fractions with the highest ACE-inhibitory activity were pooled and reapplied to the same column under the same conditions with the exception of $L$. paracasei $6 \mathrm{~A}$ fractions; these were eluted using 0 to $30 \%$ solvent B for $20 \mathrm{~min}$, then 30 to $100 \%$ for $10 \mathrm{~min}$. Fractions with the same retention time from multiple runs were pooled and dried in a chemical hood. The resulting dried residues were dissolved in HPLC-grade water, and $\mathrm{pH}$ was adjusted to 8.3. The ACE-inhibition activity of each faction was determined. The most active fraction was kept at $-20^{\circ} \mathrm{C}$ until further analysis.

\section{Matrix-Assisted Laser Desorption/lonization with Time-of-Flight Mass Spectrometer Analysis}

Matrix-assisted laser desorption/ionization with time-of-flight mass spectrometry (MALDI-TOF MS) analysis was performed on a Bruker Reflex III mass spectrometer (Bruker Daltonics, Billerica, MA) at the Ohio State University Campus Chemical Instrument Center. Briefly, a sample of the purified ACE inhibitor was mixed with the matrix at a ratio of 1:5. The matrix was cyano-4-hydroxy cinnamic acid, prepared as a saturated solution in $50 \%$ acetonitrile with $0.1 \%$ trifluoroacetic acid in water. The mixture was then spotted $(1 \mu \mathrm{L})$ on the target plate and allowed to air dry. The instrument was operated in reflection-positive ion mode at an accelerating voltage of $28 \mathrm{kV}$. The $\mathrm{N}_{2}$ laser was operated at the minimum threshold level required to generate signal and minimize dissociation.

\section{Liquid Chromatography MS/MS Analysis}

The HPLC-purified ACE-inhibitory compounds were digested by trypsin (sequencing grade; Promega, Madison, WI) in $100 \mathrm{mM}\left(\mathrm{NH}_{4}\right) \mathrm{HCO}_{3}$ buffer $\left(\mathrm{pH} \mathrm{8.0)}\right.$ at $37^{\circ} \mathrm{C}$ overnight before the reaction was quenched by adding $0.1 \%$ trifluoroacetic acid. The digests were analyzed by liquid chromatography (LC)-MS/MS for AA sequence determination. Capillary LC-nanospray tandem MS was performed on a mass spectrometer (LTQ Orbitrap; Thermo-Finnigan, Waltham, MA) equipped with a nanospray source operated in positive-ion mode (Michrom Bioresources Inc., Auburn, CA). Samples were separated on a capillary column $(0.2 \mathrm{~mm} \times 150 \mathrm{~mm}$, Magic C18AQ, 3 m, $200 \AA$ A; Michrom Bioresources Inc.) using an HPLC system (UltiMate 3000; LC-Packings, Sunnyvale, CA). Each sample was injected into the trapping column (LC-Packings) and desalted with 50 $\mathrm{m} M$ acetic acid for $10 \mathrm{~min}$. The injector port was then switched to the "inject" setting, and the peptides were eluted off the trap onto the column. Mobile phase A was $0.1 \%$ formic acid in water, and mobile phase B was $0.1 \%$ formic acid in acetonitrile. The flow rate was set at $2 \mu \mathrm{L} / \mathrm{min}$. Typically, mobile phase $\mathrm{B}$ was increased from $2 \%$ to $50 \%$ in 30 min before being increased again from $50 \%$ to $90 \%$ in $5 \mathrm{~min}$ and then kept at $90 \%$ for another 5 min before being decreased quickly to $2 \%$ in $1 \mathrm{~min}$. The column was equilibrated at $2 \%$ of mobile phase B (or $98 \%$ A) for 30 min before the next sample injection. The MS/MS spectrum was acquired with a nanospray source operated with a spray voltage of 2 $\mathrm{kV}$, and a capillary temperature of $175^{\circ} \mathrm{C}$ was used. The scan sequence of the mass spectrometer was based on the data-dependent TopTen (10 most intense peaks) method. Briefly, the analysis was programmed for a full scan recorded between 300 and 2,000 Da and an MS/ MS scan to generate product ion spectra to determine AA sequence in consecutive scans of the 10 most abundant peaks in the spectrum. The resolution of the full 
scan was set at $3 \times 10^{4}$ to achieve high-mass-accuracy MS determinations. The collision-induced dissociation fragmentation energy was set at $35 \%$.

\section{Peptide Synthesis}

Selected peptide sequences, identified by LC-MS/MS, were synthesized and tested to confirm ACE-inhibitory activities. Peptides (95-98\% purity) were synthesized by Bio Basic Canada (Markham, ON, Canada).

\section{Statistical Analysis}

Each experiment was repeated 3 times, and the results of ACE inhibition by components of milk fermentation were analyzed using the GLM procedure of SAS (version 9.4; SAS Institute Inc., Cary, NC). The ACE-inhibitory activities (\%) were compared as a function of inoculated microorganism (9 cultures and the uninoculated milk as a negative control) incubation period $(0,24,48$, and $72 \mathrm{~h})$ and fermentate fraction tested (crude extract, 3 -kDa filtrate, and 10-kDa filtrate). The statistical model tested was as follows:

$$
\begin{aligned}
& \text { ACE inhibition }(\%)=\mu+\text { microbe }+ \text { time } \\
& + \text { purification }+ \text { microbe } \times \text { time }+ \text { purification } \\
& \times \text { time }+ \text { error }
\end{aligned}
$$

where $\mu$ is the mean. Other interaction terms were removed from the model because they were not significant when a preliminary analysis was conducted. Means comparison was done using the least-significant difference function of GLM. The value of $P<0.05$ was considered significant.

\section{RESULTS}

\section{Isolation and Identification of Kombucha Culture Microorganisms}

Six bacteria and 2 yeast isolates were obtained from the green tea fermented with kombucha culture. All the bacteria isolates were gram negative. Analysis of the 16S rDNA gene for bacteria isolates showed a $98.9 \%$ similarity to Gluconobacter oxydans. Analysis of the $26 \mathrm{~S}$ rDNA gene for the 2 yeast isolates showed a $99 \%$ similarity to Dekkera anomala. A symbiotic relationship between this bacterium and the yeast results in the consortium (i.e., kombucha culture) that ferments tea to produce this unique beverage (Jayabalan et al., 2014).

\section{Changes in $\mathrm{pH}$ and Microbial Populations During Milk Fermentation}

All 8 species of LAB decreased milk $\mathrm{pH}$ from 6.6 initially to 3.9 to 4.4 after $72 \mathrm{~h}$ of fermentation. Lactic acid bacteria characteristically ferment lactose in milk producing lactic acid that lowers milk $\mathrm{pH}$. Kombucha culture modestly decreased milk $\mathrm{pH}$ from 6.6 to 6.2 within the same fermentation period. Members of kombucha culture act synergistically to ferment carbohydrates in the medium, with yeast producing ethanol and the bacterium (i.e., Gluconobacter sp.) converting the ethanol to acetic acid (Jayabalan et al., 2014). It is likely that delayed acid release resulted in the modest $\mathrm{pH}$ decrease observed.

Milk was inoculated with $1 \%$ LAB cultures, and the resulting initial population counts, as determined on MRS agar, ranged between 7.4 and $7.9 \log \mathrm{cfu} /$ $\mathrm{mL}$. Because milk used in these experiments is commercially sterile, this population reflects the LAB inoculum. This population increased during $72 \mathrm{~h}$ of incubation to 7.9 to $9.5 \log \mathrm{cfu} / \mathrm{mL}$, depending on the LAB species used.

Kombucha culture, in the form of fermented tea, was added to milk at the $1 \%$ level, and the population count in the inoculated milk was $3.7 \log \mathrm{cfu} / \mathrm{mL}$ initially. This population increased to $5.5 \log \mathrm{cfu} / \mathrm{mL}$ after $72 \mathrm{~h}$ of incubation. Considering the low selectivity of the plating medium (MRS agar), it is unlikely that these counts reflect LAB in kombucha-fermented milk. Considering that Gluconobacter sp. and Dekkera sp., which were isolated from kombucha-fermented tea, grew on MRS agar in preliminary experiments, the MRS agar count in this case represents these organisms. Three out of the 9 organisms tested (L. casei ATCC 7469, L. paracasei 6A, and kombucha culture) produced the most promising ACE-inhibitory activity. The result of milk fermentation by these 3 organisms is shown in Figure 1.

\section{Activity of Prepared ACE}

Attempts to use commercially available ACE were unsuccessful. The activity of enzyme in the commercial product deteriorated rapidly during short-term storage under the manufacturer's recommended conditions (i.e., $5^{\circ} \mathrm{C}$ ). Therefore, ACE was prepared in the laboratory from rabbit lungs (Cushman and Cheung, 1971), and the enzyme concentration was adjusted to 0.008 unit/ $\mathrm{mL}$. The enzyme preparation was held at $5^{\circ} \mathrm{C}$ until use, and its ACE activity remained fairly constant throughout the duration of the study. 


\section{Liberation of ACE Inhibitors During Milk Fermentation}

Crude extract, resulting from fermentation of milk with 8 LAB, expressed ACE-inhibitory activities at various degrees (Figure 2). The inhibitory activity generally was significantly higher $(P<0.05)$ after $72 \mathrm{~h}$ of incubation than it was at shorter incubation periods. After $72 \mathrm{~h}$ of incubation, extracts filtered through the $10-\mathrm{kDa}$ filter were significantly $(P<0.05)$ more active against ACE than those obtained from the $3-\mathrm{kDa}$ filter or the unfiltered extracts. Six LAB species produced fermentates with less than $50 \%$ inhibitory activity (data not shown). Two LAB species (L. casei and $L$. paracasei) produced milk with superior activity; their $10-\mathrm{kDa}$ filtrates obtained after $72 \mathrm{~h}$ of fermentation expressed 82 and $68 \%$ ACE inhibition, respectively (Figure 2). Although kombucha culture did not seem to grow abundantly in milk (Figure 1), the resulting fermentate had the highest ACE-inhibitory activity; $93 \%$
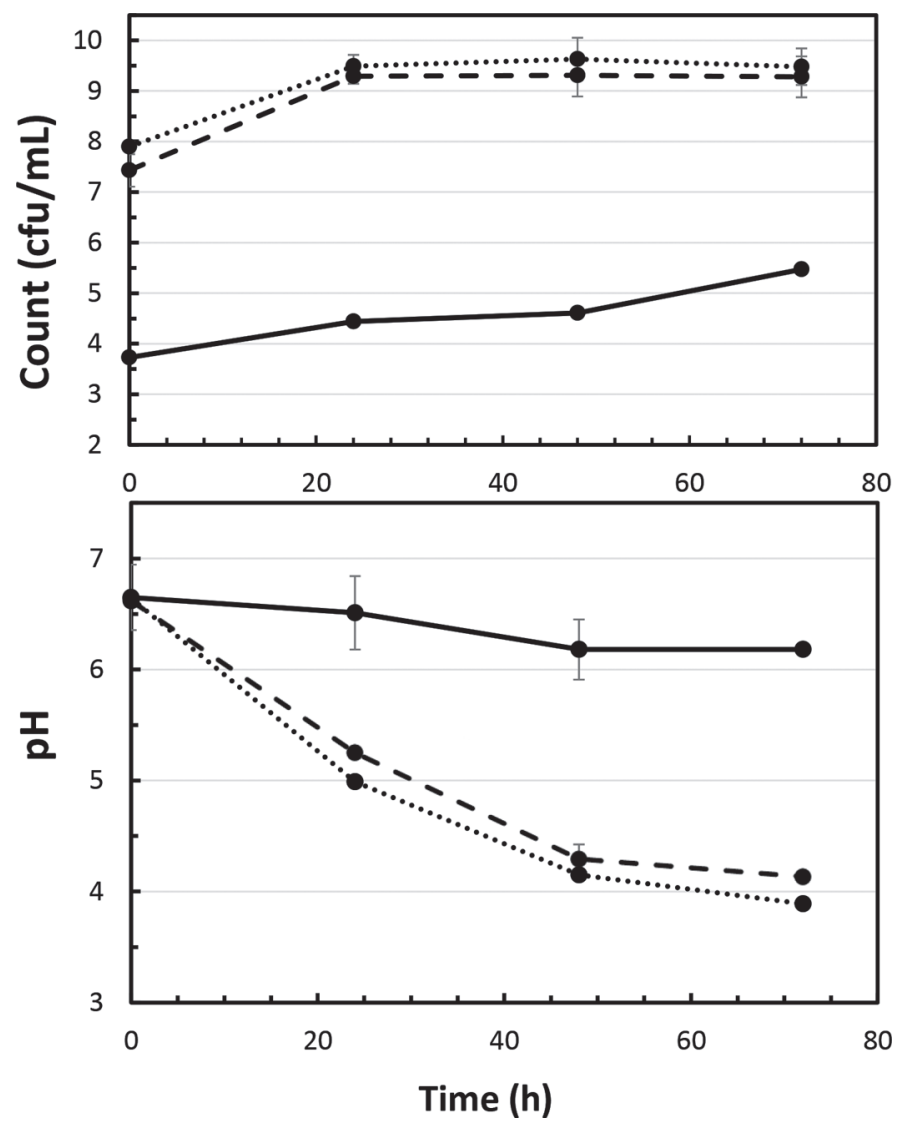

Figure 1. Changes in populations of microorganisms $(\mathrm{cfu} / \mathrm{mL})$, enumerated on De Man, Rogosa and Sharpe agar (top), and medium $\mathrm{pH}$ (bottom) during incubation of inoculated milk at $37^{\circ} \mathrm{C}$ for $72 \mathrm{~h}$. Dashed line $=$ Lactobacillus casei ; dotted line $=$ Lactobacillus paraca sei; solid line $=$ kombucha culture. Error bars represent SD.
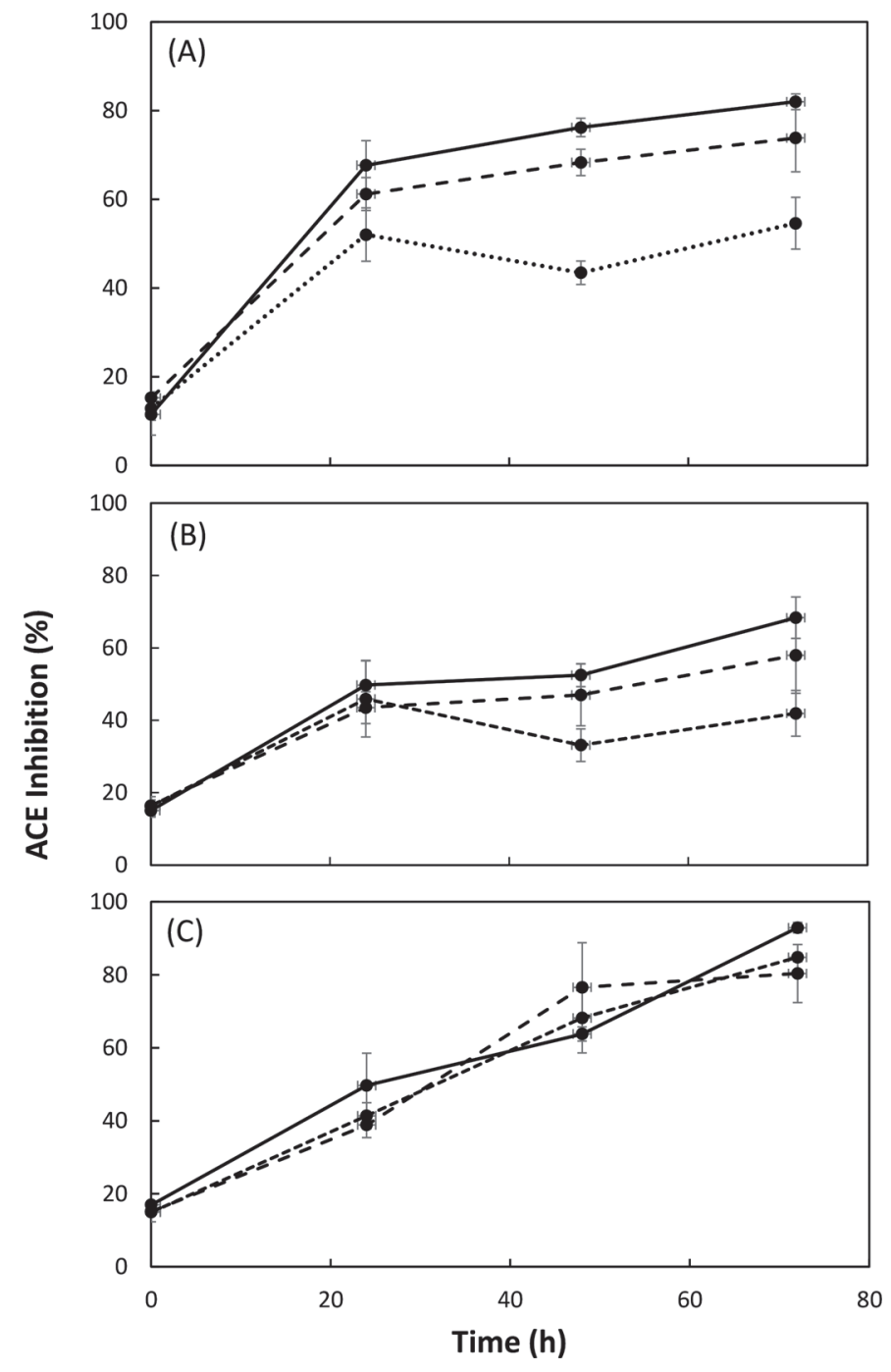

Figure 2. Changes in angiotensin-converting enzyme (ACE) percentage inhibition by extracts and filtrates of milk fermented by lactic acid bacteria and kombucha cultures at $37^{\circ} \mathrm{C}$ for $72 \mathrm{~h}$. (A) Lactobacillus casei; (B) Lactobacillus paracasei; (C) kombucha culture. Dashed line $=$ crude extract of fermented milk; dotted line $=3-\mathrm{kDa}$ filtrate; solid line $=10-\mathrm{kDa}$ filtrate. Error bars represent SD

ACE inhibition was observed in the $10-\mathrm{kDa}$ filtrate of the 72-h fermented milk (Figure 2). Results of the statistical analysis are consistent with these conclusions.

\section{ACE-Inhibitory Agents: Separation by HPLC and Characterization by MALDI TOF-MS Analysis}

Considering the high ACE-inhibitory activity of the $10-\mathrm{kDa}$ filtrates of milk fermented with $L$. casei, $L$. paracasei, and kombucha culture for $72 \mathrm{~h}$, these fractions were used to purify the active agents by HPLC. An example of HPLC chromatograms is shown for the $10-\mathrm{kDa}$ filtrate of milk fermented with $L$. casei (Figure 
$3)$. The most active HPLC fraction ( 12 -min retention time) was pooled from several runs and purified twice using similar HPLC conditions, and its ACEinhibitory activity was confirmed. When the purified fraction was subjected to MALDI TOF-MS analysis, ions with several molecular weights were detected (Figure 4). This indicates that the HPLC-purified fraction comprises multiple compounds. The same steps were repeated with the $10-\mathrm{kDa}$ filtrates of milk fermented with L. paracasei and kombucha culture. The HPLC retention times of the most active fractions from the 10-kDa filtrate of milk fermented with $L$. paracasei and kombucha culture were 8 and 15 min, respectively.

\section{Identification of Bioactive Peptides Using LC-MS/MS Analysis}

Milk fermentation by L. casei and kombucha culture resulted in the highest ACE-inhibitory activity (Figure 2 ); hence, HPLC-purified active agents from these 2 sources were studied further. These purified fractions were analyzed by LC-MS/MS to sequence potential peptides in these preparations. Results of the analysis (Tables 1 and 2; Figure 5) revealed 21 new peptide structures from these bioactive fractions. Peptides isolated from milk fermented by $L$. casei contained 7 to 12 AA residues, with molecular weights of 780.3 to 1,325.83 Da. Larger peptides were found in the HPLCpurified fraction obtained from milk fermentation by kombucha culture. These peptides vary considerably in size, with AA residues ranging between 6 and 18 and molecular weights of 688.89 to 2,044.97 Da.

Although all peptides reported in Tables 1 and 2 have smaller molecular weight than the cut-offs ( 3 and $10 \mathrm{kDa}$ ) of the filters we used to purify these peptides, generally more ACE-inhibitory activity was recovered from the $10-\mathrm{kDa}$ filter than from the $3-\mathrm{kDa}$ filter (Figure 2). It is possible that the ACE-inhibitory peptides aggregate with larger peptides, favoring their passage through the $10-\mathrm{kDa}$ filter compared with the $3-\mathrm{kDa}$ filter.

\section{Confirmation of the ACE-Inhibitory Activity of Individual Peptides}

It is not known whether some or all of the identified peptides (Tables 1 and 2) are responsible for the ACEinhibitory activity, considering our inability to separate and purify individual peptides by HPLC or other chromatographic techniques. Therefore, selected peptides were chemically synthesized and tested to confirm their ACE-inhibitory activities. Three peptides derived from milk fermentation by each of $L$. casei and kombucha cultures (Tables 1 and 2) were chosen randomly and synthesized. The concentrations of these synthetic peptides needed to inhibit $50 \%$ of the enzyme activity $\left(\mathbf{I C}_{50}\right)$ were calculated from their dose-response (concentration vs. percentage ACE inhibition) curves. An example of these curves is shown in Figure 6 . The 3 peptides derived from kombucha-fermented milk were VAPFPEVFGK, LVYPFPGPLH, and FVAPEPFVFGKEK. These exhibited high potency against ACE with $\mathrm{IC}_{50}$ values of $0.03,0.03$, and $0.75 \mu M$, respectively (Figure 5). The first of these 3 peptides has similarities with FFVAPFPEVFGK, which was reported previously as an ACE inhibitor, but with an $\mathrm{IC}_{50}$ of $77 \mu \mathrm{M}$ (Maruyama and Suzuki, 1982). The 3 peptides derived from $L$. casei fermentation and synthesized were LVESPPELNTVQ, VLESPPELN, and WGYLAYGLD. These synthetic peptides showed potent activity against $\mathrm{ACE}$, and their $\mathrm{IC}_{50}$ values were $0.11,0.23$, and 0.10 $\mu M$, respectively (Figure 5).

\section{DISCUSSION}

Bioactive peptides could be liberated during the manufacturing of milk products, either by proteases present naturally in milk (e.g., plasmin) or by bacterial starter cultures that produce several kinds of proteolytic enzymes (Ryhänen et al., 2001). Proteins in the growth media may get degraded into peptides of about 5 to 30 AA by bacterial cell-envelope proteases; these peptides are carried into the cell and further degraded by endopeptidases into smaller peptides and AA for microbial protein synthesis (Solieri et al., 2015). The endopetidases PepI, PepP, PepQ, PepR, and PepX have proline-specific hydrolytic activities that account for the main release of bioactive peptides from proline-rich $\alpha-, \beta-$, and $\kappa$-CN. Considering this evidence, it is plausible to assume that beneficial bioactive peptides could be released during milk fermentation.

Several industrially relevant LAB were tested in this study for their ability to generate ACE-inhibiting agents during milk fermentation. The lactobacilli studied include species used in the manufacture of yogurt and Italian cheeses (Kosikowski and Mistry, 1997). Lactococcus lactis is often used as a starter culture in the manufacture of many dairy products, including cottage and Cheddar cheeses (Kosikowski and Mistry, 1997). Leuconostoc spp. can be considered spoilage microorganisms (Säde, 2011); however, they are used in the manufacture of dairy products such as ymer, a Danish sour milk product (Kosikowski and Mistry, 1997). Although pediococci are most suitable for nondairy fermentations (e.g., production of fermented sausages), the $P$. acidilactici $\mathrm{PO} 2$ strain used in this study was tested previously and found to produce antimicrobial- 

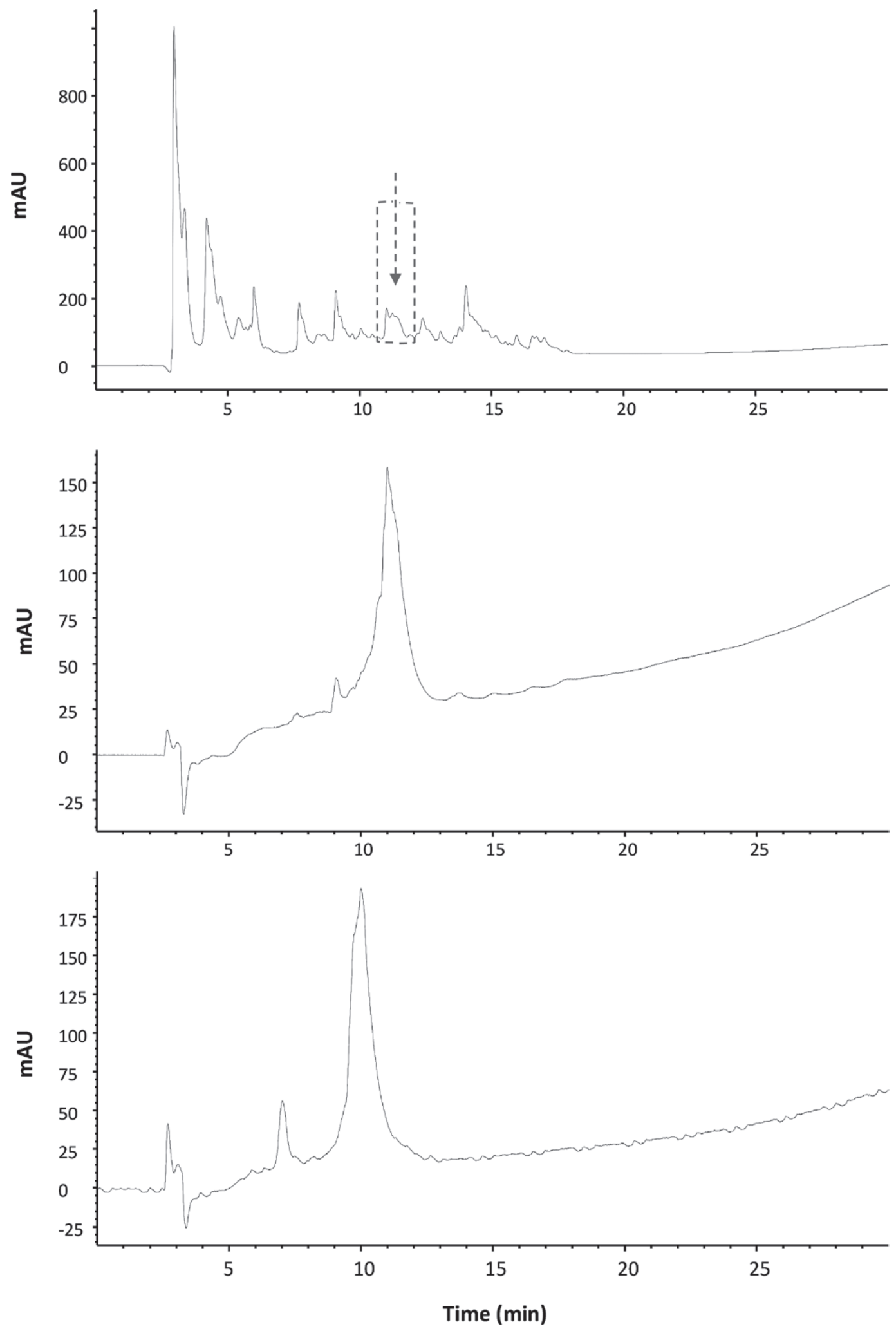

Figure 3. Reverse-phase HPLC corresponding to the 10-kDa filtrate from milk fermented with Lactobacillus casei for $72 \mathrm{~h}$. (top) An HPLC chromatogram showing retention time $(\sim 12 \mathrm{~min})$ corresponding to the fraction with highest activity against angiotensin-converting enzyme. (middle) An HPLC chromatogram resulting from the injection of the active fraction in the top panel, which has been pooled from several runs before reinjection. (bottom) An HPLC chromatogram resulting from the injection of the active fraction in the middle panel, which has been pooled from several runs before reinjection. 
rich fermented cheese whey that may be used as a protective dairy ingredient (Liao et al., 1993). Kombucha culture is used commercially to ferment sugary drinks to produce alcohol, acids, and other potentially useful bioactive metabolites (Jayabalan et al., 2014). When used in the fermentation of a rich medium such as milk, kombucha's symbiotic consortium may produce beneficial bioactive by-products. Hence, this culture was tested in this study as a potential producer of natural ACE inhibitors.

Lactobacillus sp., of starter or no-starter origin, may contribute to the production of peptides with ACEinhibitory activity in dairy products (Ryhänen et al., 2001; Chaves-López et al., 2014; Solieri et al., 2015). The current study revealed the ability of $L$. casei and L. paracasei strains to produce peptides that are potent ACE inhibitors. Additionally, we found that kombucha culture could be used in milk fermentation to liberate ACE-inhibitory peptides with very low $\mathrm{IC}_{50}$. Recently,
Hrnjez et al. (2014) used kombucha inoculum to ferment milk and tested biological activities of the resulting dairy product. The researchers detected $63 \%$ inhibition of ACE activity by the fermented milk; however, the cause of inhibition was not investigated.

The amount of ACE inhibitors released depends on the stage of fermentation. Based on the current study, $72 \mathrm{~h}$ of incubation correlated with the highest ACE activity in the fermented milk. Meisel et al. (1997) found that ACE inhibition could be low in samples with a low degree of proteolysis, but the activity increases as proteolysis proceeds up to a certain level. However, excessive proteolysis could decrease ACE-inhibitory activity in fermented dairy products (Ryhänen et al., 2001; van der Ven et al., 2002).

Several factors affect ACE-inhibitory activities exhibited by fermentation medium. Although inhibition reaction is expected to be dependent on environmental $\mathrm{pH}$, most researchers do not adjust the $\mathrm{pH}$ of bioactive-

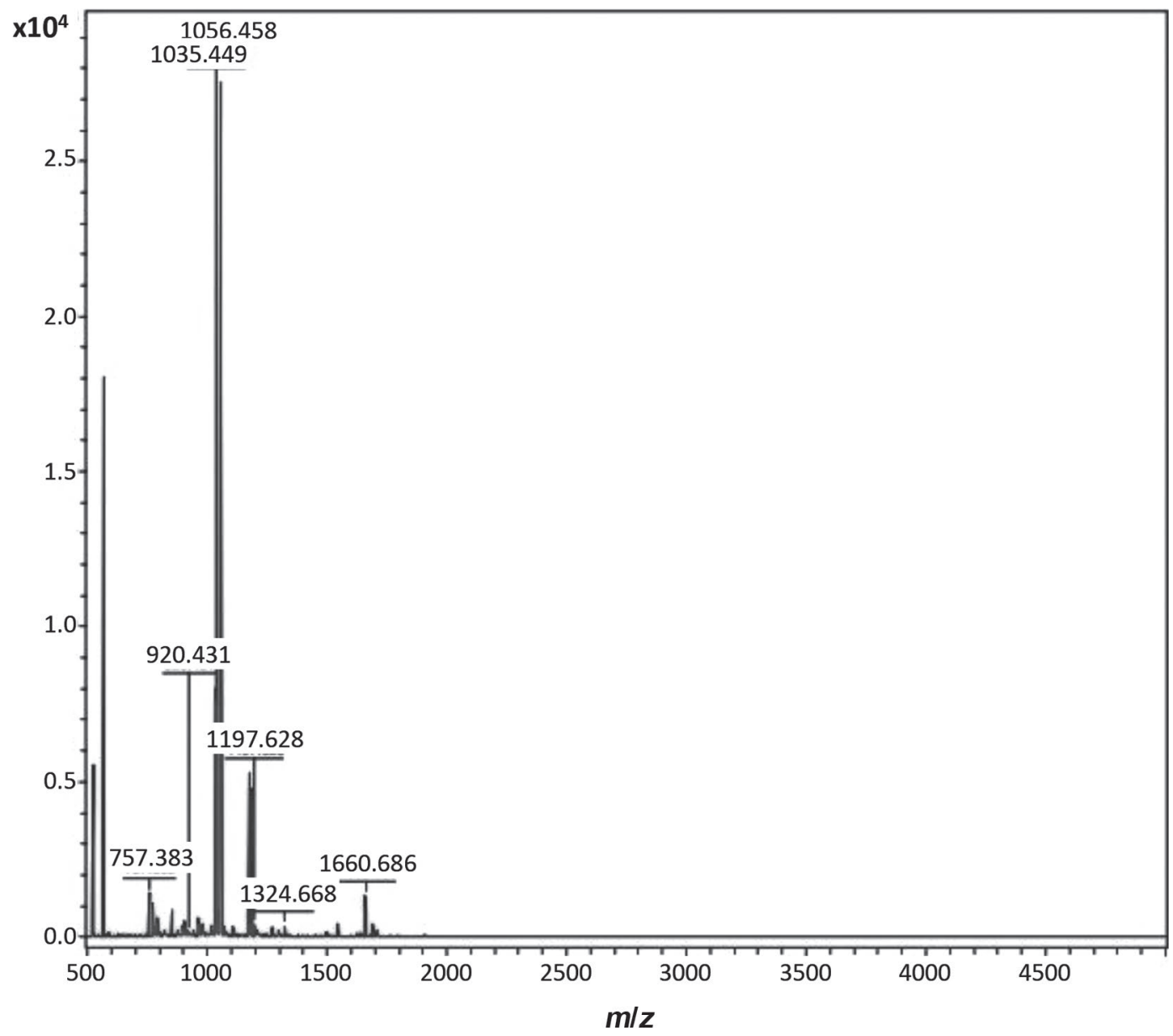

Figure 4. Matrix-assisted laser desorption/ionization with time-of-flight mass spectrometer analysis of the HPLC fraction (Figure 3, bottom panel), which was purified from milk fermented with Lactobacillus casei for $72 \mathrm{~h}$ and showed strong angiotensin-converting enzyme inhibitory activity. 

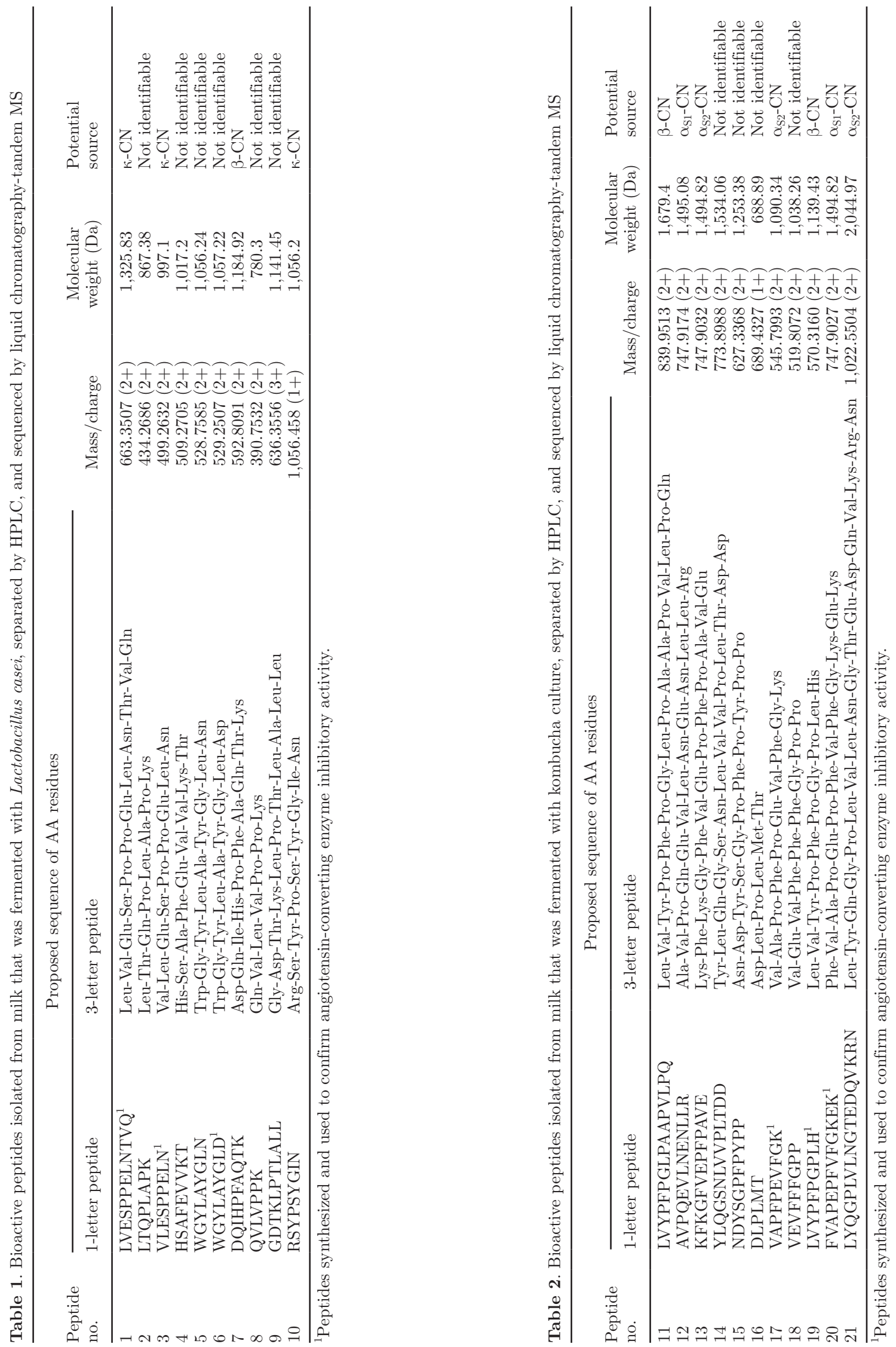


\begin{tabular}{|c|c|c|}
\hline $\begin{array}{l}\text { Peptide } \\
\text { number }\end{array}$ & Peptide alignment & $\begin{array}{l}\text { ACE } \\
\text { inhibitory } \\
\text { Activity (IC50) }\end{array}$ \\
\hline 9 & \multirow{21}{*}{ 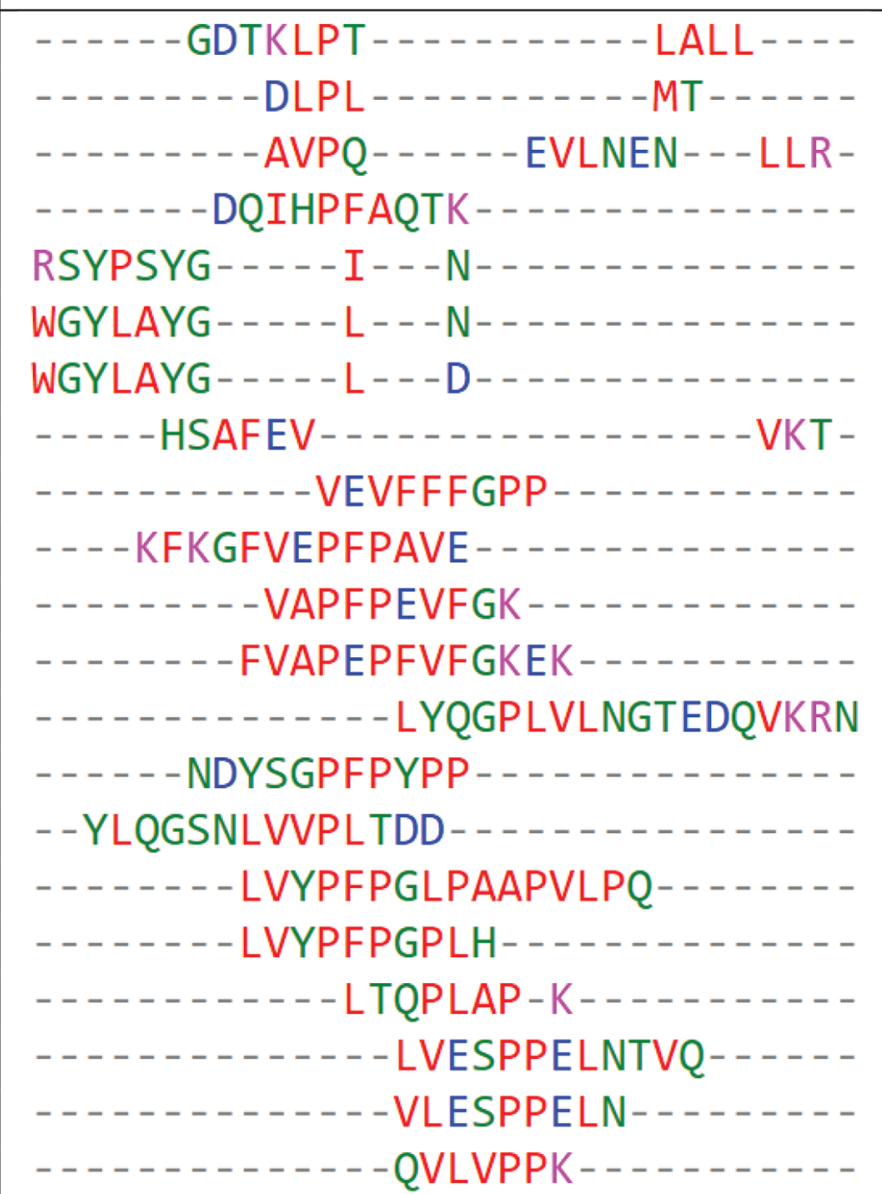 } & \\
\hline 16 & & \\
\hline 12 & & \\
\hline 7 & & \\
\hline 10 & & \\
\hline 5 & & \\
\hline 6 & & 0.10 \\
\hline 4 & & \\
\hline 18 & & \\
\hline 13 & & \\
\hline 17 & & 0.03 \\
\hline 20 & & 0.75 \\
\hline 21 & & \\
\hline 15 & & \\
\hline 14 & & \\
\hline 11 & & \\
\hline 19 & & 0.03 \\
\hline 2 & & \\
\hline 1 & & 0.11 \\
\hline 3 & & 0.23 \\
\hline 8 & & \\
\hline
\end{tabular}

Figure 5. Alignment of the angiotensin-converting enzyme (ACE) inhibiting peptides, listed in Tables 1 and 2, and the ACE-inhibitory activity of the systematic peptide analogs. Multiple sequence alignment was done using Clustal Omega software (EMBL-EBI, 2017). Color version available online.

containing media before examining the inhibitory activity of ACE. We found it crucial to adjust the $\mathrm{pH}$ to 8.1 to 8.3 to obtain meaningful and comparative results. Gonzalez-Gonzalez et al. (2011) found that ionic calcium released during milk fermentation could increase the ACE-inhibitory activity. Contribution of ionic calcium was not investigated when synthetic peptides were tested in the current study.

Many researchers have investigated the structureactivity relationship of biologically active peptides. Foltz et al. (2009) modeled the relationship between the structure of 228 synthetic dipeptides and their ACE-inhibiting activities. The researchers developed a model to predict ACE-inhibitory activity based on the structure of the dipeptide. Compared with the study by Foltz et al. (2009), application of quantitative struc- ture-activity relationship on natural ACE-inhibiting peptides is less feasible considering the shortage of large sets of these peptides and the potential variability in activity testing among different research groups. In the current study, we aligned the 21 new peptides, but only limited structural similarities were revealed (Figure 5). We also attempted to relate the ACE-inhibitory activities to peptide primary structure. Peptides 1 and 3 were found to share the Pro-Pro-Glu-Leu-Asn sequence, and both are potent ACE inhibitors (Figure 5). Considering that this is a small data set, conclusions about structure-function relationship cannot be drawn with high confidence.

In conclusion, fermentation of milk using L. casei ATCC 7469 can liberate potent ACE-inhibitory peptides such as LVESPPELNTVQ, VLESPPELN, and 


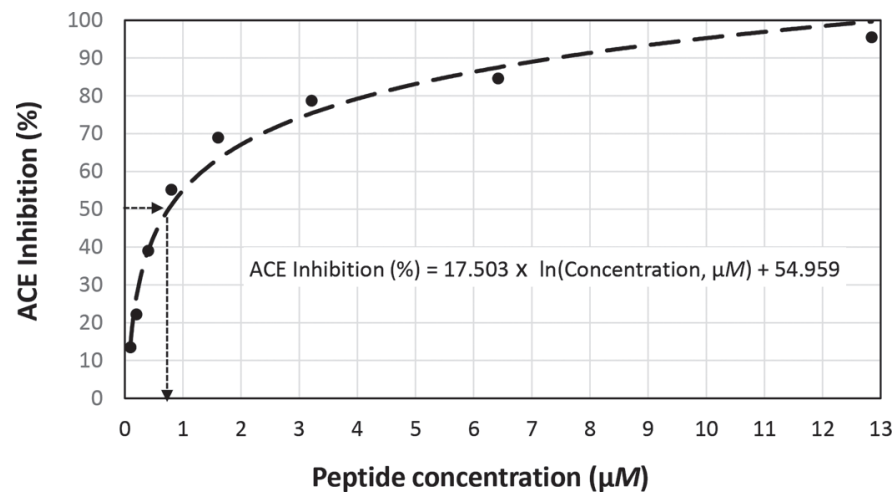

Figure 6. Dose-response curve to determine the concentration of the active synthetic peptide at its $50 \%$ inhibition level $\left(\mathrm{IC}_{50}\right)$ against angiotensin-converting enzyme (ACE). The experiment was done on a synthetic peptide (FVAPEPFVFGKEK) analogous to that produced by Lactobacillus casei. Figure insert shows the equation used to fit the dose-response curve and calculate the $\mathrm{IC}_{50}$.

WGYLAYGLD. Milk fermented with kombucha culture also contained several ACE-inhibitory peptides such as VAPFPEVFGK, LVYPFPGPLH, and FVAPEPFVFGKEK. Although the source of these peptides is presumed to be milk proteins (Tables 1 and 2), this does not exclude the potential de novo synthesis of these peptides by the LAB or kombucha cultures. Additional studies are needed to confirm the source of these bioactive peptides and their ability to reduce hypertension in experimental animals and humans. Additional research also is needed to optimize production of these peptides during fermentation and explore the commercial feasibility of enhancing fermented products in these peptides.

\section{ACKNOWLEDGMENTS}

This study was funded by the Cultural Affairs and Missions sector, Ministry of Higher Education and Scientific Research, Cairo, Egypt. Additional funding was provided by the Ohio Agricultural Research and Development Center, The Ohio State University, Columbus. We acknowledge the technical help provided by En Huang and David Kasler (Department of Food Science and Technology, The Ohio State University) and Lewin Zhang (Campus Chemical Instrument Center, The Ohio State University).

\section{REFERENCES}

Atkinson, A. B., and J. I. Robertson. 1979. Captopril in the treatment of clinical hypertension and cardiac failure. Lancet 2(8147):836839.

Bauman, D. E., I. H. Mather, R. J. Wall, and A. L. Lock. 2006. Major advances associated with the biosynthesis of milk. J. Dairy Sci. 89:1235-1243.
Chaves-López, C., A. Serio, A. Paparella, M. Martuscelli, A. Corsetti, R. Tofalo, and G. Suzzi. 2014. Impact of microbial cultures on proteolysis and release of bioactive peptides in fermented milk. Food Microbiol. 42:117-121.

Chen, G.-W., J.-S. Tsai, and B. S. Pan. 2007. Purification of angiotensin I-converting enzyme inhibitory peptides and antihypertensive effect of milk produced by protease-facilitated lactic fermentation. Int. Dairy J. 17:641-647.

Cole, J. R., Q. Wang, J. A. Fish, B. Chai, D. M. McGarrell, Y. Sun, C. T. Brown, A. Porras-Alfaro, C. R. Kuske, and J. M. Tiedje. 2014. Ribosomal Database Project: Data and tools for high throughput rRNA analysis. Nucleic Acids Res. 42:D633-D642.

Cushman, D. W., and H. Cheung. 1971. Spectrophotometric assay and properties of the angiotensin-converting enzyme of rabbit lung. Biochem. Pharmacol. 20:1637-1648.

EMBL-EBI. 2017. Clustal Omega, multiple sequence alignment. Accessed September 20, 2017. http://www.ebi.ac.uk/Tools/msa/ clustalw2/.

Foltz, M., L. van Buren, W. Klaffke, and G. Duchateau. 2009. Modeling of the relationship between dipeptide structure and dipeptide stability, permeability, and ace inhibitory activity. J. Food Sci. 74:H243-H251.

Gonzalez-Gonzalez, C., K. Tuohy, and P. Jauregi. 2011. Production of angiotensin-I-converting enzyme (ACE) inhibitory activity in milk fermented with probiotic strains: Effects of calcium, $\mathrm{pH}$ and peptides on the ACE-inhibitory activity. Int. Dairy J. 21:615-622.

Haque, E., R. Chand, and S. Kapila. 2009. Biofunctional properties of bioactive peptides of milk origin. Food Rev. Int. 25:28-43.

Hernández-Ledesma, B., L. Amigo, M. Ramos, and I. Recio. 2004. Application of high-performance liquid chromatography-tandem mass spectrometry to the identification of biologically active peptides produced by milk fermentation and simulated gastrointestinal digestion. J. Chromatogr. A 1049:107-114.

Hrnjez, D., Ž. Vaštag, S. Milanović, V. Vukić, M. Iličić, L. Popović, and K. Kanurić. 2014. The biological activity of fermented dairy products obtained by kombucha and conventional starter cultures during storage. J. Funct. Foods 10:336-345.

Jäkälä, P., A. Hakala, A. M. Turpeinen, R. Korpela, and H. Vapaatalo. 2009. Casein-derived bioactive tripeptides Ile-Pro-Pro and ValPro-Pro attenuate the development of hypertension and improve endothelial function in salt-loaded Goto-Kakizaki rats. J. Funct. Foods 1:366-374.

Jayabalan, R., R. V. Malbasa, E. S. Loncar, J. S. Vitas, and M. Sathishkumar. 2014. A review on kombucha tea-Microbiology, composition, fermentation, beneficial effects, toxicity, and tea fungus. Compr. Rev. Food Sci. Food Saf. 13:538-550.

Kitts, D. D., and K. Weiler. 2003. Bioactive proteins and peptides from food sources. Applications of bioprocesses used in isolation and recovery. Curr. Pharm. Des. 9:1309-1323.

Kosikowski, F. V., and V. V. Mistry. 1997. Cheese and Fermented Milk Foods, Volume II: Procedures and Analysis. 3rd ed. F. V. Kosikowski LLC, Westport, CT.

Kurtzman, C. P., and C. J. Robnett. 1998. Identification and phylogeny of ascomycetous yeasts from analysis of nuclear large subunit (26S) ribosomal DNA partial sequences. Antonie van Leeuwenhoek 73:331-371.

Liao, C.-C., A. E. Yousef, E. R. Richter, and G. W. Chism. 1993. Pediococcus acidilactici $\mathrm{PO}_{2}$ bacteriocin production in whey permeate and inhibition of Listeria monocytogenes in foods. J. Food Sci. 58:430-434.

López-Fandiño, R., J. Otte, and J. Van Camp. 2006. Physiological, chemical and technological aspects of milk-protein-derived peptides with antihypertensive and ACE-inhibitory activity. Int. Dairy J. 16:1277-1293.

Maruyama, S., and H. Suzuki. 1982. A peptide inhibitor of angiotensin I converting enzyme in the tryptic hydrolysate of casein. Agric. Biol. Chem. 46:1393-1394.

Meisel, H., A. Goepfert, and S. Gunther. 1997. ACE-inhibitory activities in milk products. Milchwissenschaft 52:307-311. 
Niarchos, A. P., T. G. Pickering, D. B. Case, P. Sullivan, and J. H. Laragh. 1979. Role of the renin-angiotensin system in blood pressure regulation. Circ. Res. 45:829-837.

Prado, M. R., L. M. Blandón, L. P. S. Vandenberghe, C. Rodrigues, G. R. Castro, V. Thomaz-Soccol, and C. R. Soccol. 2015. Milk kefir: Composition, microbial cultures, biological activities, and related products. Front. Microbiol. 6:1177.

Quirós, A., M. Ramos, B. Muguerza, M. A. Delgado, M. Miguel, A. Aleixandre, and I. Recio. 2007. Identification of novel antihypertensive peptides in milk fermented with Enterococcus faecalis. Int. Dairy J. 17:33-41.

Reiss, J. 1994. Influence of different sugars on the metabolism of the tea fungus. Z. Lebensm. Unters. Forsch. 198:258-261.

Ryhänen, E.-L., A. Pihlanto-Leppälä, and E. Pahkala. 2001. A new type of ripened, low-fat cheese with bioactive properties. Int. Dairy J. 11:441-447.

Säde, E. 2011. Leuconostoc spoilage of refrigerated, packaged foods. PhD Dissertation. University of Helsinki, Helsinki, Finland

Sancho, J., R. Re, J. Burton, A. C. Barger, and E. Haber. 1976. The role of the renin-angiotensin-aldosterone system in cardiovascular homeostasis in normal human subjects. Circulation 53:400-405.

Schanbacher, F. L., R. S. Talhouk, F. A. Murray, L. I. Gherman, and L. B. Willett. 1998. Milk-borne bioactive peptides. Int. Dairy J. 8:393-403.
Solieri, L., G. S. Rutella, and D. Tagliazucchi. 2015. Impact of nonstarter lactobacilli on release of peptides with angiotensin-converting enzyme inhibitory and antioxidant activities during bovine milk fermentation. Food Microbiol. 51:108-116.

van der Ven, C., H. Gruppen, D. B. de Bont, and A. G. Voragen. 2002. Optimisation of the angiotensin converting enzyme inhibition by whey protein hydrolysates using response surface methodology. Int. Dairy J. 12:813-820.

Weisburg, W. G., S. M. Barns, D. A. Pelletier, and D. J. Lane. 1991 $16 \mathrm{~S}$ ribosomal DNA amplification for phylogenetic study. J. Bacteriol. 173:697-703.

World Health Organization. 2013. A Global Brief on Hypertension: Silent Killer, Global Public Health Crisis. WHO, Geneva, Switzerland.

Yamada, Y., R. Hosono, P. Lisdyanti, Y. Widyastuti, S. Saono, T. Uchimura, and K. Komagata. 1999. Identification of acetic acid bacteria isolated from Indonesian sources, especially of isolates classified in the genus Gluconobacter. J. Gen. Appl. Microbiol. $45: 23-28$. 